\title{
AS ESCOLAS COM JORNADA AMPLIADA NO MUNICÍPIO DE ARAÇATUBA: A PESQUISA E UMA EXPERIÊNCIA CONJUGADA
}

\author{
Raquel Pozzenato Silazaki, Renata Portela Rinaldi \\ Universidade Estadual Paulista - UNESP, Faculdade de Ciências e Tecnologia, Programa de Pós-Graduação em \\ Educação, Presidente Prudente, SP. E-mail: rpsilazaki@hotmail.com
}

\begin{abstract}
RESUMO
Este trabalho apresenta um recorte da pesquisa desenvolvida dentro do PPGE da FCTUnesp/Presidente Prudente, no Sistema Municipal de Ensino de Araçatuba-SP, com os Coordenadores Pedagógicos (CoP) do Ensino Fundamental I, das Escolas de Tempo Integral e de Atividades Complementares. Abordou as concepções acerca da formação desses profissionais e seus processos de aprendizagem profissional. Como parte do trabalho e da coleta de dados foi desenvolvida uma ação de formação continuada com os CoP. No encaminhamento desse processo formativo surgiu o interesse por conhecermos a realidade estadual, tendo sido concretizadas duas visitas em escolas estaduais, com jornada ampliada. De abordagem qualitativa, a pesquisa se desenvolveu pelas vias bibliográfica, documental e pela coleta de dados, de perspectiva construtivo-colaborativa (COLE; KNOWLES, 1993), de pesquisa-intervenção. A experiência foi riquíssima e permitiu conhecer realidades distintas das escolas municipais, validou-se como um processo que conjugou desafios, inquietações, mas, acima de tudo, muito aprendizado.

Palavras-chave: Coordenação Pedagógica. Processo de Aprendizagem Profissional. Educação Integral. Escolas com Jornadas Ampliadas. Experiência conjugada.
\end{abstract}

\section{EXTENDED HOURS' SCHOOLS IN THE MUNICIPALITY OF ARAÇATUBA: RESEARCH AND A CONJUGATED EXPERIENCE.}

\begin{abstract}
This paper presents a part of the research developed within the Post Praduate Program in Education of the FCT - UNESP/PRESIDENTE PRUDENTE, in the Municipal Educational System of Araçatuba-SP, with the Elementary School's Pedagogical Coordinators (CoP) of Full-Time and Complementary Activities Schools. It addressed the conceptions about the training of these professionals and their professional learning processes. As part of the work and data collection an ongoing training course was developed with the CoP's. In conducting this training process, emerged the interest in knowing the State reality, and two visits were made to state schools with extended hours. Of qualitative approach, the research was developed through bibliographic, documentary and data collection, from a constructive-collaborative perspective (COLE; KNOWLES, 1993), of intervention research. The experience was very rich and allowed to know different realities of the municipal schools, validated as a process that combined challenges, concerns, but, above all, learning.
\end{abstract}

Keywords: Pedagogical Coordination. Professional Learning Process. Full-Time Education. Extended Hours' Schools. Conjugated Experience. 


\section{INTRODUÇÃO}

A partir do tema proposto para o ENEPE 2018, temos observado que a implantação de tecnologias e estratégias de ensino e aprendizagem têm requerido, sobretudo, nas primeiras décadas do século XXI, considerável atenção por parte das instituições educacionais que buscam atender as novas gerações que estão altamente conectadas, num mundo cada vez mais fluido, no qual informações e conhecimentos circulam amplamente e sem barreiras. Lidar com as novas gerações, conectadas o tempo todo, têm exigido mudanças em diferentes contextos. Na educação temos observado o propósito de criar alternativas que se efetivem em práticas inovadoras e que coloquem o indivíduo em formação (e social), em constante interação e capaz de desenvolver competências (muito em voga no momento) para, assim, viver em sociedade com a possibilidade de se adaptar às diferentes exigências que o mundo contemporâneo tem revelado e exigido.

Oferecer mecanismos que favoreçam a autonomia, o desenvolvimento de habilidades e competências na atualidade requer, além de investimentos, muitas discussões em torno das temáticas que estão sendo colocadas em jogo nos últimos tempos, sobre novos ambientes de aprendizagens, novos tempos e espaços para as práticas educativas etc. Propor questões como essas nos ambientes institucionais formativos são fundamentais para que, não só no Ensino Superior ou nos programas de Pós-Graduação ela proporcione resultados, mas que, significativamente, reverberem e ofereçam caminhos/mecanismos para que toda a Educação Básica possa superar os inúmeros desafios que ainda estão presentes na oferta de uma educação de qualidade.

Não temos dúvidas que, quando se discute sobre novos ambientes de aprendizagem e, sobretudo, novos tempos e espaços para as práticas educativas que envolvem crianças e jovens que chegam à escola já integrados e conectados com diferentes tipos de recursos tecnológicos, redes sociais e informações diversas, temos sempre um amplo debate a ser feito em torno de como está e como se concretiza a oferta do ensino hoje no país. É enorme a reponsabilidade para com a formação desses indivíduos, de lhes permitir acesso a conhecimentos que de fato lhes atribua sentido, permita o desenvolvimento cognitivo e social, inclusive, para melhor lidarem, a cada dia, com que o mundo tecnológico e globalizante oferece, numa sociedade capitalista.

Aliado a essas questões temos visto a implantação de diferentes políticas públicas difundidas em nível nacional e que exigem dos sistemas de ensino, ações que favoreçam sua concretização, investimentos financeiros, formações, além de indivíduos muito comprometidos com o alunado 'globalizado' presente nas escolas. Uma dessas políticas foi trabalhada na pesquisa desenvolvida no Sistema Municipal de Ensino de Araçatuba, município do interior do Estado de São Paulo que envolveu as escolas com jornadas ampliadas, assim denominadas: Escolas de Tempo Integral (ETI) ${ }^{1}$ e de Atividades Complementares $(A C)^{2}$, a partir da ação e atuação dos Coordenadores Pedagógicos $(\mathrm{COP})^{3}$ dessas escolas. A Investigação formalizou-se na linha de pesquisa "Formação dos Profissionais da Educação, Políticas Educativas e Escola Pública" do Programa de Pós-Graduação em Educação da Faculdade de Ciências e Tecnologia da Universidade Estadual Paulista (Unesp), Campus de Presidente Prudente. Investigou as ações voltadas à formação continuada e à atuação dos CoP, compreendidos por nós como formadores de professores da Educação Básica (RINALDI, 2009), que focalizou, contudo, seu desenvolvimento profissional e os desafios pertinentes à sua prática no contexto dessas escolas de jornadas ampliadas.

Assim, temos como objetivo neste trabalho apresentar parte do processo de desenvolvimento dessa pesquisa quando, a partir do interesse dos CoP, juntamente com a pesquisadora, surgiu a possibilidade de conhecer duas escolas com jornadas ampliadas da rede

\footnotetext{
${ }^{1}$ ETI, abreviatura que será usada no corpo deste texto, para denominar Escola de Tempo Integral.

${ }^{2} \mathrm{AC}$, para escola com Atividades Complementares.

${ }^{3}$ CoP, para Coordenadores Pedagógicos.
} 
estadual de ensino, ambas oferecem o Ensino Fundamental II e o Ensino Médio. Dentre as diversas aprendizagens que a pesquisa nos proporcionou envolvendo as escolas municipais e seus CoP, tivemos a possibilidade de ampliar o olhar (ainda que não profundamente) sobre essas escolas estaduais que recebem parte dos alunos da rede municipal.

\section{O CONTEXTO DA PESQUISA}

O Sistema Municipal de Ensino de Araçatuba conta, atualmente, com 64 unidades escolares, sendo: 04 com Educação Infantil e Ensino Fundamental I, oferecidos concomitantemente; 36 de Educação Infantil; 24 de Ensino Fundamental. Dessas 24, temos, neste ano de 2018, 11 escolas que são de ETI ou de AC. Trabalhamos na pesquisa, especificamente, com 10 unidades com jornadas ampliadas, sendo que em 2017, ano que finalizamos a investigação, foi implantada a 11a escola com AC. O Quadro 1 demostra a natureza das escolas envolvidas na pesquisa.

Quadro 1. Natureza das ETI/AC do Sistema Municipal de Ensino de Araçatuba.

\begin{tabular}{|l|l|}
\hline $\begin{array}{l}\text { Modelos de } \\
\text { ETI/AC e no de } \\
\text { unidades }\end{array}$ & Natureza/características \\
\hline $\begin{array}{l}\text { Escola de Tempo } \\
\text { Integral (ETI) - 8 } \\
\text { un. }\end{array}$ & $\begin{array}{l}\text { 4 Escolas estaduais, advindas no processo de municipalização. Processo que } \\
\text { ocorreu em etapas. Na terceira e última fase, em 2007, o município recebeu } \\
\text { essas 4 unidades de jornada ampliada (ensino regular e oficinas curriculares } \\
\text { para todos os alunos). Somaram-se, no decorrer dos anos seguintes, outras } \\
4 \text { unidades de ETI, como forma de ampliação do atendimento nesta } \\
\text { modalidade de ensino, pelo sistema municipal. }\end{array}$ \\
\hline $\begin{array}{l}\text { Escola com } \\
\text { Atividade } \\
\text { Complementar } \\
\text { (AC) - 3 un. }\end{array}$ & $\begin{array}{l}\text { Escolas com a ampliação da jornada no contraturno, somente para alguns } \\
\text { alunos da unidade escolar, nos dois períodos, manhã ou tarde, somando-se } \\
\text { a essa perspectiva de ampliação do atendimento no sistema em jornadas } \\
\text { ampliadas. }\end{array}$ \\
\hline
\end{tabular}

Fonte: Elaboração própria com base na pesquisa desenvolvida (SILAZAKI, 2017).

Até o início do ano de 1999, a educação municipal de Araçatuba atendia a Educação Infantil e a Educação de Jovens e Adultos. A partir desse mesmo ano, passou a oferecer também o primeiro ciclo do ensino fundamental, em prédios próprios do município, além do desencadeamento do processo de municipalização que absorveu 18 escolas estaduais, sendo 4 delas ETI, advindas na terceira e última fase da municipalização em 2007. No decorrer dos anos seguintes consolidamos, então, o universo de 64 unidades escolares, sendo 11 desse montante, em jornada ampliada, como especificado no Quadro 1.

A Lei Complementar (LC) municipal, LC nㅇ 125/2003 possibilitou, pela primeira vez, a designação para a função de CoP, mas, à época, somente para as escolas que ofereciam o Ensino Fundamental I, excetuando-se a Educação Infantil. Essa lei foi revogada pela LC no 204/2009 que, em regulamentação ao Estatuto, Plano de Carreira, Vencimentos e Salários do Magistério Público do Município de Araçatuba, propôs novos critérios para e escolha dos CoP e, desta vez, possibilitando sua designação para a Educação Infantil, retratando um ganho para essas escolas.

Brevemente destacamos o contexto da pesquisa, reconhecendo nessa trajetória a figura do CoP que vivenciou o crescente desenvolvimento de um sistema de ensino, pautado pelas exigências legais e estruturais fundamentais à educação, que seguiram avançando ao longo das últimas décadas do século passado até o momento atual. O município assumiu a responsabilidade pelas ETI/AC e, desde então, tem enfrentado inúmeros desafios técnicos, administrativos e pedagógicos na consolidação da oferta do ensino, cenário em que destacamos a figura do CoP, 
como formador de professor. Estes viveram e vivem uma dinâmica e complexa prática, inúmeros desafios de natureza pedagógica, sobretudo, em contextos de formação continuada, pelos quais são responsáveis. Observada toda essa dinâmica, a pesquisadora, que faz parte deste sistema municipal de ensino, buscou revelar os caminhos trilhados por eles, nessa complexa especificidade de escolas com jornadas ampliadas.

A investigação finalizada perpassou pela estruturação de uma formação continuada de 180 horas, na modalidade de aperfeiçoamento ${ }^{4}$, oferecido, especificamente, sob a perspectiva de abordar aspectos que envolviam o cotidiano escolar dos CoP, seus desafios e experiências. No decorrer de 10 encontros de formação, e dentre as inúmeras leituras, reflexões, aprendizagens, experiências vividas e angústias divididas, surgiu no grupo de CoP, a vontade, manifestada pelos participantes, de conhecerem outras realidades escolares com jornada ampliada, de modo que pudessem observar diferentes e notórios contextos estrutural e formas de trabalho que servissem de exemplo e parâmetros para sustentar as análises que o grupo passou a fazer sobre a própria prática, na realidade municipal.

\section{METODOLOGIA}

A investigação da qual faz parte este recorte, apoiou-se na pesquisa qualitativa que direcionou os caminhos percorridos. Pautou-se nessa vertente e percorreu uma trajetória para descobrir o sentido conferido às funções e atribuições do CoP, sobretudo, em relação aos processos formativos pelos quais esse profissional se torna responsável quando assume a função da coordenação pedagógica, e exigem a busca de caminhos mais profícuos para a sua trajetória nas ETI/AC. Assim, a pesquisa qualitativa [...] "busca dar sentido aos significados dos fenômenos que ocorrem por meio dos fatos e locais que constituem seus objetos". (CHIZZOTTI, 2003. p. 221), ampliando o conhecimento em torno de todo o processo investigativo desenvolvido com esses profissionais.

Destacamos nessa pesquisa, o compromisso ético assumido com os participantes e o Comitê de Ética em Pesquisa com Seres Humanos (CAAE 53868316.6.0000.5402), percorrendo um processo de interação contínua, em que os aspectos levantados pelos participantes foram todos considerados importantes. Assim, a interação e a compreensão das realidades vividas pelos CoP, ocorreram de uma forma dialógica, de modo que pesquisador e pesquisados, compartilhassem saberes na vertente construtivo-colaborativa (COLE; KNOWLES, 1993; RINALDI 2009), de pesquisaintervenção, para que todos pudessem aprofundar os conhecimentos sobre as ETI/AC, sobre a educação integral e nelas intervir num processo de desenvolvimento profissional.

Perpassamos pela pesquisa bibliográfica, que nos permitiu ampliar os conhecimentos em torno da temática, além disso perceber os diversos enfoques que permeiam a produção acadêmica/científica, permitindo-nos a construção de novos conhecimentos. A pesquisa documental balizou o entendimento, sobretudo, para compreender quem é este profissional, o CoP. Por fim, a coleta de dados, por meio do trabalho empírico, que se formalizou com a formação continuada oferecida, pela aplicação do grupo dialogal e do questionário. Todos os encontros de formação (total de dez) oferecidos, foram filmados e transcritos com base no protocolo NURC. As análises sobre a coleta de dados empíricos foram orientadas à luz da análise de conteúdo, momento em que foram levantadas as categorias e subcategorias de análises, trilhando um caminho de significados apoiado [...] "numa concepção de ciência que reconhece o papel ativo do sujeito na produção do conhecimento" (FRANCO, 2012, p.10).

\footnotetext{
${ }^{4}$ Certificado pela Pró-Reitoria de Extensão Universitária (PROEX) da Unesp.
} 


\section{RESULTADOS}

Com o desejo dos CoP em conhecerem a realidade estadual, a partir dos enfoques trabalhados na formação continuada, promovemos a primeira visita na Escola Estadual " $\mathrm{A}^{\prime 5} \mathrm{em}$ Araçatuba (de Ensino Fundamental II e Ensino Médio), que desenvolve o Programa de Ensino Integral do Estado de São Paulo. A escola visitada foi uma indicação de uma das CoP do sistema municipal, que participa de algumas atividades em parceria com essa escola estadual e, tendo a ciência sobre o diferencial do programa lá existente, motivou os participantes da pesquisa a conhecerem àquela realidade. Foi uma experiência enriquecedora para seis CoP e para a pesquisadora deste trabalho.

A visita à escola revelou-se, então, como parte do processo formativo, pois o grupo de gestores da escola estadual expuseram os objetivos do programa, as concepções e as experiências vividas com os alunos, bem como abriram a oportunidade para questionamentos que pudessem clarificar quaisquer dúvidas surgidas no momento da visita.

Sugeriram que formalizássemos uma outra visita na Escola " $\mathrm{B}^{\text {" }}$, também no município de Araçatuba, pois alegaram que essa escola possuía um perfil de ampliação de jornada semelhante ao do sistema municipal e que, por essa razão, uma visita nessa realidade poderia contribuir com o conhecimento dos participantes, especialmente para o enfrentamento dos desafios de implantação das ETI/AC, que se desenvolve no município pesquisado. Informaram que há diferentes especificidades (de concepções, formas e estrutura curricular) entre as escolas que são Escolas de Tempo Integral (Escola B) e escolas que são do Programa de Ensino Integral (Escola A) do estado de São Paulo e que, portanto, em virtude de alguns diferenciais entre elas valeria uma visita na outra realidade.

De fato foi concretizada a visita na Escola B, diretora e coordenadora da escola expuseram sob suas rotinas, sobre os profissionais atuantes nessa escola, sobre o envolvimento dos alunos por meio do Grêmio Estudantil, sobre o monitoramento e acompanhamento das aprendizagens dos alunos etc. A CoP da escola B recebe formação mensal na Diretoria Regional de Ensino, ambas, diretora e coordenadora entendem como extremamente necessárias as formações para os profissionais inseridos nesse contexto, reconhecem e veem como extremamente positiva a ETI.

Um dos destaques para essas realidades foi para o número de profissionais que elas dispõem para o desenvolvimento dos trabalhos. Em relação ao município, o número de profissionais é bem maior nas duas realidades do sistema estadual de ensino. Diferentemente do município, naquela época (dois anos atrás) não possuíam problemas com a falta de professores, pois ocorrendo a falta, de uma forma ou outra sempre será colocado outro professor no lugar.

As gestoras das duas unidades escolares visitadas também apontaram para a questão da verba, que foi baixa ou nem existiu, no ano de 2016, expuseram os desafios para atenderem as necessidades e manutenções das escolas. Fato que chamou a atenção dos CoP municipais, uma vez que a dificuldade de manter uma unidade de jornada ampliada com pouca, ou nenhuma verba, influi significativamente no trabalho de todos os envolvidos.

Por fim, na escola A que desenvolve o Programa de Ensino Integral do Estado todos os professores, coordenadores e os diretores exercem tutoria com os alunos, cada um deles se responsabiliza por um número $\mathrm{X}$ de alunos, a tutoria é acadêmica e pessoal/familiar, cada tutor responsabiliza-se por reunir-se com os pais de seus alunos e tratam sobre o que diz respeito a integralidade do aluno. Uma prática que nos pareceu muito produtiva e favorecedora à aprendizagem dos alunos e ao seu desenvolvimento pessoal e social.

\footnotetext{
${ }^{5}$ Caracterizada como A, de modo a manter seu anonimato.

${ }^{6}$ Caracterizada como B, de modo a manter seu anonimato. 


\section{DISCUSSÕES}

As experiências nessas escolas, não previstas inicialmente, foram muito significativas para o grupo de CoP e pesquisadora que visitaram tais realidades. Olhar sob o ponto de vista do outro é necessário, ouvir os depoimentos, os exemplos, os desafios e os problemas narrados por outras pessoas que estão em realidades parecidas (pelas jornadas ampliadas) permitiram perceber que, guardadas as proporções, todas elas são desafiadoras, apresentam problemas, dificuldades com recursos financeiros, mas acima de tudo, tem muitas pessoas comprometidas para fazer o melhor pela formação integral do aluno e por oferecer uma educação mais significativa, visando sua qualidade.

A formação continuada oferecida por meio da pesquisa desenvolvida, possibilitou conhecer e ampliar a visão dos CoP sobre a escola de tempo integral, sobre a educação integral, a ponto de se interessarem por conhecer novas realidades. Desta forma, destacamos o quanto foi valiosa a experiência formativa. Titton e Pacheco (2012) mencionam sobre a formação continuada:

Essa formação pode constituir-se em espaços para a construção de competências e de identidades; o delineamento de papéis e a partilha de responsabilidades; a visibilidade de representações sociais; o confronto de trajetórias individuais; a compreensão de conflitos epistemológicos e para o questionamento de culturas profissionais e institucionais. (TITTON; PACHECO, 2012, p. 155)

As questões mencionadas por essas autoras se fizeram presentes ao longo do processo formativo e, ao participar das visitas nas escolas estaduais, tivemos a oportunidade de olhar por outros muros a realidade de escolas com jornadas ampliadas do município em que a pesquisa aconteceu. Embora não tivesse sido o objetivo da pesquisa, ela desenvolveu-se como uma possiblidade de formação do CoP, que puderam vivenciar um aprendizado significativo, por meio do diálogo e do acolhimento, que as experiências proporcionaram.

\section{CONCLUSÃO}

Essa possibilidade vivenciada por meio da pesquisa desenvolvida com os CoP, foi uma experiência significativa que contribuiu para ampliar o pensamento sobre a escola da Educação Básica (de jornada ampliada para uma educação integral) e sobre as necessidades de seu alunado e profissionais envolvidos. Como já mencionamos, o surgimento de diversas temáticas, novos recursos ou novas tecnologias, novos ambientes, tempos e espaços diferenciados de aprendizagem, assim como as diferentes políticas públicas que estão em desenvolvimento no país nos trazem inúmeras questões e inquietações. Por isso, requerem que seus sentidos e significados sejam de fato compreendidos e assimilados, de modo a permitir que a escola/universidade ofereça uma educação transformadora para seus alunos, que estão cada vez mais conectados e necessitam saber lidar com as diferentes situações que estão presentes na sociedade.

\section{REFERÊNCIAS}

COLE, L.; KNOWLES, J. G. Teacher Development partnership research: a focus on methods and issues. American Educational Reasearch Journal, v. 30, n. 3, 1993, p. 473-495. https://doi.org/10.3102/00028312030003473

SILAZAKI, R. P. O processo de aprendizagem profissional de coordenadores pedagógicos para as/ nas escolas de/em tempo integral no município de Araçatuba. 2017. 259 f. Dissertação (Mestrado em Educação) - Universidade Estadual Paulista (UNESP), Faculdade de Ciências e Tecnologia, Presidente Prudente. 
CHIZzOTTI, A. A pesquisa qualitativa em ciências humanas e sociais: evolução e desafios. Revista Portuguesa de Educação, v. 16, n. 2, 2003, p. 221-236. Universidade do Minho Braga, Portugal. Disponível em: < http://www.redalyc.org/articulo.oa?id=37416210> Acesso em: 05 ago. 2017.

RINALDI, R. P. Desenvolvimento Profissional de Formadores em Exercício: contribuições de um programa on-line. 2009. 231f. Tese (Doutorado em Educação) - Universidade Federal de São Carlos - UFSCar, São Carlos.

TITTON, M. B. P.; PACHECO, S. M. Educação integral: a construção de novas relações no cotidiano. In: MOLL, J. (Org.). Caminhos da Educação Integral no Brasil: direito a outros tempos e espaços educativos. Porto Alegre: Penso, 2012, p. 149-156.

FRANCO, M. L. P. B. Análise de Conteúdo. 4 ed. Brasília: Liber Livro, 2012. 